infections, multiple sclerosis, toxin, trauma, or unknown factors. ${ }^{1}$ In these patients the aetiology of pure trigeminal motor neuropathy remains obscure, but a possible cause is an infection, probably viral, affecting the motor division of the trigeminal nerve. Differences in the specificity of membrane proteins in the trigeminal motor and sensory systems may account for susceptibility of the motor neurons to specific viral infections. The first three patients had initial symptoms of a common cold, which might suggest a viral infection. Alternatively, the condition might have been idiopathic. We found no evidence for induction of pure trigeminal motor neuropathy from clinical data, computed tomography of the brain, skull radiographs, or electrophysiological examinations in cases 4 and 5 . Recently, Jannetta found that most cases of idiopathic trigeminal sensory neuropathy and trigeminal neuralgia were due to vascular compression of the trigeminal nerve, ${ }^{1}$ which might also apply to our cases.

1 Jannetta PJ, Robbins LJ. Trigeminal neuropathy-new observation. Neurosurgery 1980;7:347-51. 2 Weintraub E, Soltani K, Hekmatpanah J, Lorincz AL. Trigeminal trophic syndrome. F Am Acad Dermatol 1982;6:52-7.

3 Mokri B. Raeder's paratrigeminal syndrome. Arch Neurol 1982;39:395-9.

4 Kimura J. An evaluation of the facial and trigeminal nerves in polyneuropathy. Neurology 1971;21:745-52.

5 Chia LG, Chu FL. A clinical and electrophysiological study of patients with polychlorinated biphenyl poisoning. F Neurol Neurosurg Psychiat 1985;48:894-901.

(Accepted 28 October 1987)

Section of Neurology, Taichung Veterans General Hospital, Taichung, Taiwan 40705, People's Republic of China

LIE-GAN CHIA, MD, head of section

\section{Microvascular fragility and acute mountain sickness}

Hunter et al reported increased capillary fragility in three subjects at high altitude and speculated on the likely relation between this phenomenon and the genesis of acute mountain sickness. ${ }^{1}$ We took the opportunity of an expedition by the Royal Navy, Royal Marines Mountaineering Club to Mount Kenya to examine the effect of a rather abrupt ascent to $4300 \mathrm{~m}$ on microvascular fragility and to look for any association with acute mountain sickness.

\section{Subjects, methods, and results}

We studied 20 men and two women (mean age 30 (range 21-56)) using the method of Hunter et al described by Stirrups et al. ${ }^{12}$ Using the barrel of a $2 \mathrm{ml}$ syringe $(1 \mathrm{~cm}$ diameter) we applied a subatmospheric pressure of $200 \mathrm{~mm} \mathrm{Hg}$ to the buccal mucous membrane of the lower lip for one minute, and the petechiae produced were counted. Two sites were used on each occasion in each subject. We made measurements on two days in Nairobi (altitude $1300 \mathrm{~m}$; control values) and on the first two days after arrival at base camp $(4300 \mathrm{~m})$, which was reached 30 hours after leaving Nairobi. This ascent resulted in acute mountain sickness in most of the subjects: one subject required evacuation with severe symptoms, two were entirely free of symptoms, and the rest suffered varying degrees of sickness during the third to fifth days at altitude.

The figure shows that the number of petechiae increased at high altitude in only four subjects, did not change in two, and decreased in 16. The mean number of petechiae, measured at two sites on two days, was significantly lower at high altitude $(11 \cdot 4 v 4 \cdot 5, \mathrm{p}<0.01$ with Wilcoxon's signed rank test; the distribution of petechiae was appreciably skewed). There was no significant correlation between symptom scores and the number of petechiae either at Nairobi or at high altitude.

\section{Comment}

Our findings indicate that the hypoxia at $4300 \mathrm{~m}$ does not increase microvascular fragility during the first two days after arrival at this altitude, when acute mountain sickness is developing. Indeed, we found significantly fewer petechiae than at low altitude. Possibly the increased fragility found by Hunter $e t$ al was due to the greater altitude at which they made their observations $(4750 \mathrm{~m}$ and $6000 \mathrm{~m})$; their data did not show an increase at $3000-4000 \mathrm{~m}$. Acute mountain sickness is, however, common at $3000-4000 \mathrm{~m}$; thus if microvascular fragility is important in the aetiology of acute mountain sickness one would expect it to be increased after a rapid ascent to that altitude and to be correlated with symptom scores. The test might possibly produce more petechiae after more time at altitude, but any factor important to the mechanism of acute mountain sickness must operate in the first two days.

We use the term microvascular fragility as there is no evidence that it is capillary rather than venular rupture that causes petechiae.

Hunter $e t$ al also suggested that subjects with inherently more fragile microvasculature, as evidenced by more petechiae on testing at low altitude,

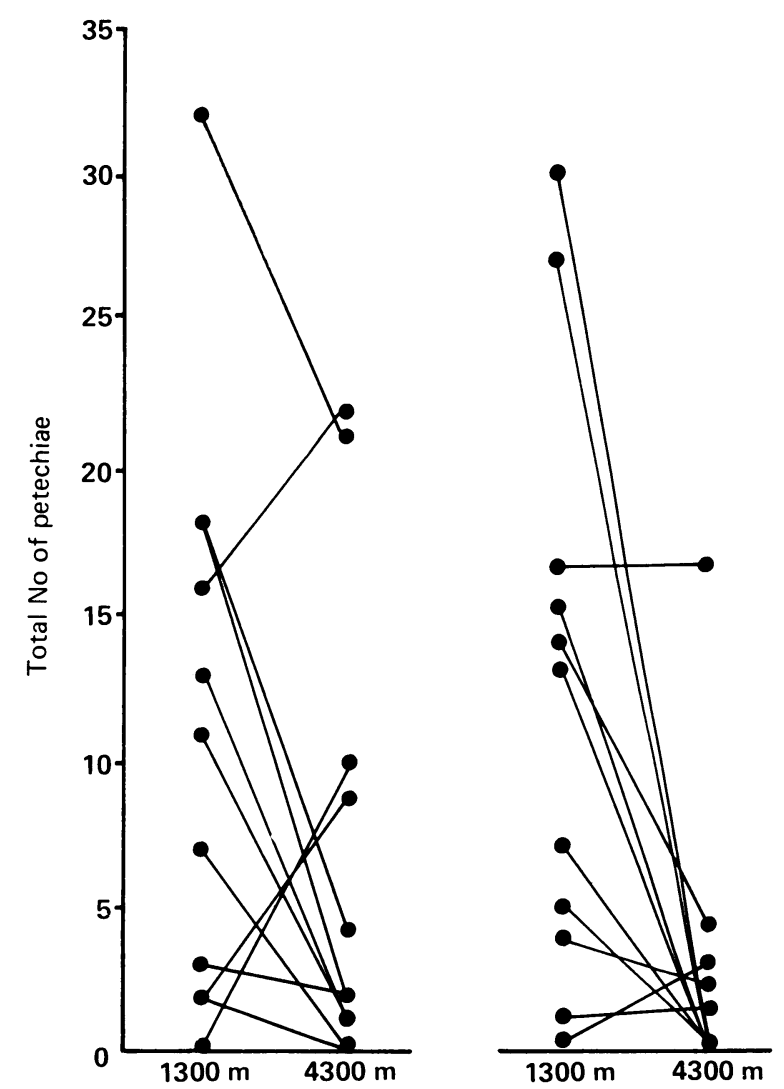

Total number of petechiae counted in two sites on two days in each subject at Nairobi $(1300 \mathrm{~m})$ and at base camp $(4300 \mathrm{~m})$. Lines join numbers at low and high altitudes for each subject. For clarity data are presented in two groups.

might be more susceptible to acute mountain sickness. ${ }^{1}$ We tested this possibility on our data by plotting the result of the test at Nairobi against symptom scores. There was a weak positive correlation, but this was not significant $(\mathrm{r}=0 \cdot 27)$.

We conclude that an increase in fragility induced by hypoxia and an inherently fragile microvasculature are not important factors in susceptibility to acute mountain sickness.

We thank all the expedition members and especially Sublieutenant D Robinson, Royal Navy, and Senior Aircraftman P Jiggins, Royal Air Force, for their technical help.

1 Hunter DJ, Smart JR, Whitton L. Increased capillary fragility at high altitude. Br Med $\mathcal{J}$ 1986;292:98.

2 Stirrups DR, Orth DD, Dinsdale RC. Mucosal petechiometry: a reliable method for the measurement of capillary resistance. Br f Oral Surg 1977;14:230-9.

(Accepted 29 October 1987)

Clinical Research Centre, Northwick Park Hospital, Harrow, Middlesex HA1 3UJ

J S MILLEDGE, MD, FRCP, consultant physician

Royal Naval Hospital Haslar, Gosport, Hampshire

J R BROOME, MRCP, occupational medicine specialist J M BEELEY, FRCP, consultant physician

Correspondence to: Dr Milledge. 